\title{
Development and Usability Testing of SOMO, a Mo- bile-Based Application to Monitor Social Functioning for Youth at Clinical High-Risk for Psychosis
}

\author{
Olga Santesteban-Echarri ${ }^{1,2}$, Jacky Tang ${ }^{1}$, Jaydon Fernandes ${ }^{1} \&$ Jean Addington ${ }^{1,2^{*}}$ \\ ${ }^{1}$ Hotchkiss Brain Institute, Department of Psychiatry, University of Calgary, Calgary, Alberta Canada. \\ 2 The Mathison Centre for Mental Health Research \& Education, Department of Psychiatry, University of Calgary, Calgary, Alberta Canada.
}

\begin{abstract}
Background: Youth at clinical high-risk (CHR) for developing psychosis are characterized by long-standing social deficits and isolation compared to healthy youth. Because poor social functioning is predictive of transition to psychosis, it is important to monitor its fluctuations.

Objective: To describe the development of a mobile application to monitor social functioning for CHR youth. Methods: App development was divided into two phases. In Phase 1, three focus groups with up to eight CHR participants were conducted to discuss (i) content, (ii) graphic design, and (iii) user experience of the app. A working prototype was developed, debugged, and systematically tested by developers. In Phase 2, 13 participants (nine CHR individuals and four healthy controls) evaluated the app through a usability testing for one week. Feedback was gathered through the 23-item Mobile Application Rating Scale user-version (uMARS). Participants were questioned further regarding improvements, positive, and negative aspects of each of the uMARS' items and app features. Focus groups and uMARS' qualitative data were audio-recorded, transcribed verbatim, and analyzed through an inductive approach.

Results: The app was named SOMO and incorporated five features: 1) home screen; 2) goal setting; 3) 11 daily questions; 4) a calendar; and 5) feedback. The application monitored number of daily in-person and online interactions, meaningfulness and time spent with each person, conflict and conflict resolution, activities performed, subjective perception of socialization, and loneliness. SOMO received a good overall score in the uMARS: an excellent score in safety, close to an excellent score in functionality; good scores in information, aesthetics and subjective quality; and acceptable scores in engagement.

Conclusion: Co-design with youth through focus groups provided effective feedback for developing SOMO, which demonstrated initial usability and acceptability. Future research should robustly test the app for efficacy, safety, and should determine that it is a valid and reliable measure of social functioning for the CHR population.

Keywords: mobile health, smartphone, at-risk, psychosis, youth, application
\end{abstract}

Article History

Received 9 October 2019

Revised 10 December 2019

Accepted 10 December 2019

DOI 10.24989/dp.v1i1.1806

\section{Introduction}

A major research focus in the psychosis field is youth who are at clinical high-risk (CHR) for developing psychosis. These individuals present with attenuated or subthreshold psychotic symptoms and typically have poor social and role functioning (Fusar-poli et al., 2012). Although less than a third may develop a full-blown psychotic illness within two years (Fusar-Poli et al., 2012), the majority, even those who do not transition to psychosis, are characterized by long-standing social deficits and isolation compared to healthy youth (Addington et al., 2018). If left untreated, these deficits can lead to profound disability, regardless of the presence or severity of the attenuated psychotic symptoms. Furthermore, both poor initial social functioning as well as a decline in social functioning over time are predictive of later transition to psychosis (Addington et al., 2019; Addington et al., 2017; Brucato et al., 2017). Current methods of assessing and monitoring social functioning are limited to infrequent clinician rated scales such as the Global Functioning: Social (GF:S; Cornblatt et al., 2007), or the Social and Occupational Functioning Assessment Scale (SOFAS; Morosini, Magliano, Brambilla, Ugolini, \& Pioli, 2000). There is a need to develop tools to assess social functioning in a dynamic and ecologically valid way (Alvarez-Jimenez et al., 2019). Tracking youth' responses in (near) real-time ensures minimal data loss and early detection of any decline in social functioning. Without this, we remain dependent on single-point retrospective measures that do not capture the dynamics of the adolescent's social interactions or when a decline may occur. Daily assessments can be easily undertaken using new technologies such as smartphones. Today, $90 \%$ of 
youth in Canada own a mobile phone (Pew Research Centre, 2019). Moreover, psychiatric patients, especially those under 30 , show favorable attitudes to using their smartphones to monitor their symptoms (Torous et al., 2014). Given youth's enthusiasm for mobile-based applications, these platforms may provide cost-effective, anonymous, non-stigmatizing, and continuously available support to CHR youth (McDermott et al., 2010).

However, the development of mobile-based applications faces several challenges such as user interface design, information architecture, and application context (König-Ries, 2009), which may interfere with the usability of apps by specific populations. To reduce some of these difficulties, participatory design (i.e. involving the user from the beginning to the end of the development of a mobile-based application; Scandurra, Hägglund, \& Koch, 2008) has been proposed as a useful approach in creating a highly usable application that matches users' idiosyncratic needs. Participatory design through focus groups aims to design mHealth applications (Hamzah, 2018) with users, rather than for users, by involving them throughout the development process (Sanders, 2002). Participatory design usually involves three phases: (i) initial exploratory work mostly done by researchers; (ii) the discovery process, which is when most interaction occurs between researchers and users; and (iii) the prototyping phase by iteratively shaping artifacts (Spinuzzi, 2005). The most common methods for data collection in participatory design are semi-structured interviews, focus groups, workshops, or organizational games (Spinuzzi, 2005). Among others, participatory design can use different techniques to: (i) create tangible artifacts such as collages, probing, and prototyping; (ii) explain things such as storyboarding using diaries, blogs, or pictures; and (iii) act and play by using games or improvisation (Sanders, Brandt, \& Binder, 2010).

Focus groups have been previously used with youth and adolescents to gather information regarding mHealth tools and user needs. These have generally been useful in obtaining information about safety, engagement, accessibility, functionality, type of information captured, and features to be included in mobile apps (Hetrick et al., 2018; Kenny, Dooley, \& Fitzgerald, 2014; Lim et al., 2019; Reid et al., 2009). Adolescents and young adults are capable of providing valuable feedback related to mHealth tools and their features such as avatars, social interaction, frequency, duration, timing, and mode of delivery (Cornelius et al., 2013). Specifically, youth have an interest in smartphone applications promoting behavior change that includes tracking behaviors, setting personal goals, and getting information (Dennison, Morrison, Conway, \& Yardley, 2013).

There are some mobile-delivered interventions dedicated to improving social functioning such as FOCUS for schizophrenia (Ben-Zeev et al., 2014), and +Connect (Lim et al., 2019) and myCompass (Fogarty et al., 2017) for depression and anxiety. SPAN (Social Participation and Navigation) implements social goal-setting for adolescents with a traumatic brain injury (Narad et al., 2018), and MATS (Mobile Assessment and Treatment for Schizophrenia) monitors socialization attitudes through four daily text messages for individuals with schizophrenia (Granholm, Ben-Zeev, Link, Bradshaw, \& Holden, 2012). However, none have included daily monitoring of functioning comprising a diverse range of self-reported social aspects. Therefore, we have developed SOMO, an application to monitor daily social activity among youth at CHR. This article describes the development and testing phases of the app. To the best of our knowledge, this is the first time a tool has been developed to exclusively monitor social functioning, an important predictor of transition to psychosis and impairment in those at CHR for psychosis.

\section{Methods}

\subsection{Sample}

Participants were identified from current studies at the AtRisk for Mental Illness Research Program at the University of Calgary. When youth attended one of their follow-up assessments, they were asked if they would like to participate in an app study. Inclusion criteria were: 1) meet criteria for one of the three established criteria for a psychosis-risk syndrome (i.e. attenuated psychotic symptom state, brief intermittent psychotic state, or genetic risk with deterioration in functioning) based on the Structured Interview for Psychosis-Risk Syndromes (McGlashan, Walsh, \& Woods, 2010); 2) ages between 12-30 years old; and 3) understand and provide signed informed consent. Ethics approval from the Conjoint Health Research Ethics Board (CHREB) was obtained for the focus groups and usability testing. All participants provided informed consent to participate in this project (parental informed consent and assent were obtained for those under the age of 18) and for the use of the material created in the focus groups for publication purposes.

\subsection{Procedure}

Phase 1 (Development): Three 90-minute focus groups were conducted (June-August, 2018) with a maximum of 10 and a minimum of four participants per group (Heary \& Hennessy, 2002). Focus groups were facilitated by OSE, a doctoral level clinical psychologist with experience in focus groups, and co-facilitated by two undergraduates who worked on the app development (JT, JF). The first group (June 2018) focused on app content. Opinions were gathered on the existing paper tools that measure social functioning such as the Global Functioning: Social (GF:S; Cornblatt et al., 2007). See Supplementary Material for a full list of tools consulted. The second group (June 2018) focused on the graphic design in two parts: (1) Participants were shown current existing apps on the market that assess similar outcomes (i.e., goals, relationships, social skills) and participants generated opinions and design ideas; (2) Following Design Studio methodology (Warfel, 2009), participants were prompted to create freestyle sketches of the features they would want in the app, which 
were subsequently discussed by the group (see Supplementary Material eFigure 1). The third group (August 2018) focused on user experience. Participants reviewed a working prototype of the app and were prompted initial in-group testing to offer feedback on features, design, speed of the app, data storage, and iterate on the design further. Participants were reimbursed $\$ 30$.

Phase 2 (Usability Testing): The app was tested systematically on iOS and Android devices by the app developers (alpha-testing). Participants then tested the app (beta-testing) for one week (December, 2018) and were provided quantitative and qualitative feedback on their experience with SOMO. Of the 13 participants, four were healthy controls with no prior experience of the app; five were CHR participants with no prior experience of the app; and four were CHR participants who previously participated in at least one focus group. Participants were reimbursed $\$ 90$.

\subsection{Measures}

To obtain feedback about the app following the usability testing, the Mobile Application Rating Scale user-version (uMARS; Stoyanov, Hides, Kavanagh, \& Wilson, 2016) was utilized. This is a 5-point Likert scale [1=poor, 2=fair, 3=acceptable, 4=good, and $5=$ excellent $]$ with 23 items covering questions about engagement, functionality, aesthetics, information, subjective quality, and perceived impact. All of the subscales can be evaluated by their mean score. The uMARS has demonstrated good testretest reliability $(\mathrm{ICC}=.70)$ and excellent internal consistency ( $\alpha=.90$; Stoyanov et al., 2016), showing good internal consistency in our sample $(\alpha=.82)$. One question regarding perceived safety was added. The uMARS was implemented in interview form, where participants provided their quantitative rating for each item, and the interviewer prompted further questioning to gather qualitative information (i.e. on improvements, positive and negative aspects) for each of the uMARS items. No attempt was made to analyze the perceived impact, as it was beyond the scope of the article.

\subsection{Data analyses}

The focus groups and the qualitative interviews were audiorecorded and transcribed verbatim. For Phase 1, a general inductive approach was employed for analysis (Thomas, 2006). Transcripts were summarized and used in conjunction with the design sketches to underscore the main app design and features. The three focus groups were analyzed as a whole dataset (Braun \& Clarke, 2013). When specific research questions guide the focus groups (i.e. app features), results can be extracted with focused objectives (Thomas, 2006). OSE coded the main themes and features and JT checked for accuracy until data saturation was obtained (Guest, Bunce, \& Johnson, 2006). For Phase 2, descriptive information about the semi-structured interview process and the quality ratings through the uMARS were reported.

\section{Results}

\subsection{Development of the app}

Ten participants were invited to each of the three focus groups. Eight participants confirmed that they would attend focus groups 1 and 2. For focus group 3, only six participants confirmed, and two did not attend due to a last-minute schooling conflict. Eight participants attended the first focus group (age: $M=20.0, S D=3.5$, range: 15.6 to $27.0 ; 62.5 \%$ female), eight attended the second (age: $M=19.7, S D=3.6$, range: 15.6 to $27.0 ; 75 \%$ female), and four the third focus group (age: $M=20.2, S D=1.4$, range: 18.4 to $21.4 ; 75 \%$ female). Participants created the name of the app SOMO (SOcial MOnitoring) and its logo. Below, we describe the general design and the development of each SOMO feature after qualitative information was gathered (i.e., home screen, goal-setting, questions, calendar, and feedback). Figure 1 depicts the initial design showed to participants.

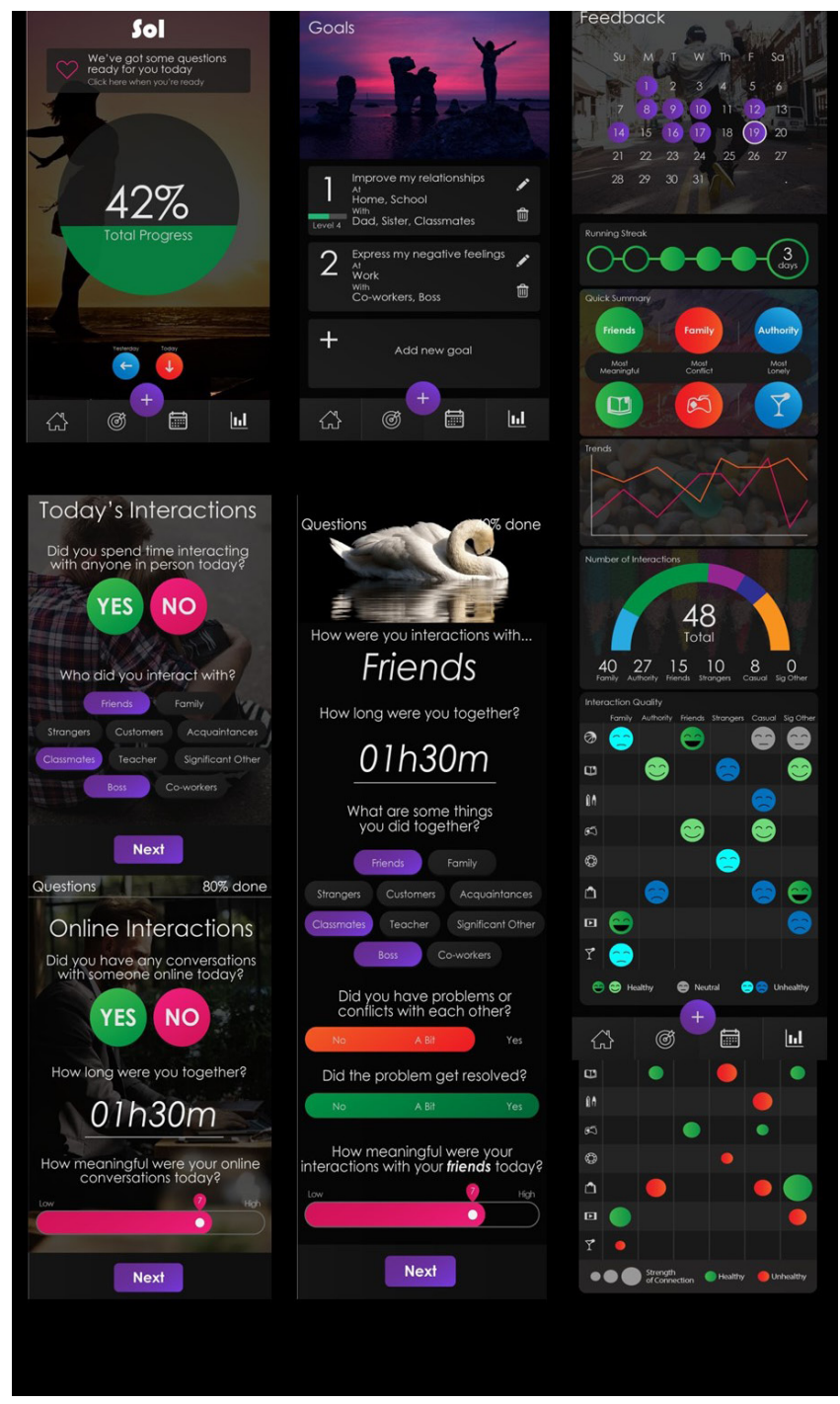

Figure 1. Initial application design. 


\subsection{General Design and Settings}

Development was guided by the Technology Acceptance Model (TAM; Davis, 1989), which suggests that engagement with an app and its continued usage is the result of its perceived ease of use and perceived usefulness. Thus, key development aspects to take into account in monitoring apps are quick completion of questionnaires, app performance, and ease of use (Price, Sawyer, Harris, \& Skalka, 2016).

Participants chose a user-friendly design including: minimal steps to access content; "info buttons" on each screen to facilitate understanding; simple screen arrangements and wording; a minimal amount of text; and graphics instead of text for the feedback. Moreover, participants made clear they wanted more neutral pictures (e.g. no gender, age, or people represented), opting for images of nature or urban backgrounds.

Participants expressed the importance of facilitating a degree of customization within the app, which ranged from changing the background themes or the color palette to having an individualized notification system. The youth discussed the need to have a reminder to $\log$ in to SOMO (e.g. setting up an alarm for a specific hour). They unanimously wanted an automatically pushed single notification on their phone screen. Although they thought the app was straightforward, there were concerns about older generations not being used to the technology, or the younger people needing more onboarding assistance when they are first introduced to the app. Thus, they expressed the need for a tutorial.

Data safety was important. Participants did not want to provide any personal information or contacts and proposed a password-protected app to safeguard their privacy. User privacy was managed by (i) a 4-digit PIN login and (ii) encrypted transmission of anonymous data stored on secure servers managed by the University IT department. Furthermore, participants expressed the concern that monitoring apps do not provide extra support in case of distress. Consequently, a phone icon directly connected to a free $24 \mathrm{hr}$ counseling center in Calgary was incorporated into the app.

\subsection{App features}

Home screen. Participants liked the initial home screen design because it was simple, intuitive, and not overwhelming. Participants wanted some basic statistics to reinforce usage and to have a general idea of their social relations: "maybe you can show a mood tracker, a percentage, or something right away on the home screen." Thus, displaying the percentage of total interactions was implemented as quick feedback on the home screen. Quick access to the daily questionnaire occurred by touching one of the two reminders integrated into the home screen (e.g., today and/or the previous day) when they had not yet been completed. Finally, a bug report button was implemented to al- low real-time usability testing and users to report any technical problems.

Daily questions. Out of the initial set of 18 daily questions presented, a final set of 11 questions focusing on in-person or online social interactions were implemented, covering: type of relationship, time spent together, quality of the interaction, activities undertaken, conflict and resolution, meaningfulness of the interaction, and the subjective feelings about the amount of social engagement and perceived loneliness. All app questions are presented in the Supplementary Material. Participants assisted in wording and selecting the priority foci of the questions (e.g. less importance to online interactions) to make the questionnaire short but useful. Questions that were not implemented covered: (i) how the interaction started (i.e. we ran into each other; I contacted them, etc.); (ii) conflict resolution strategies (i.e. we talked about it); (iii) perceived supportiveness and perceived connection of the interaction; and (iv) type of online interaction (i.e. messaged, video-chat, Snapchat, etc.) or online conflict and resolution. Participants thought that some of these questions did not add useful information to their social functioning, were not easily distinguishable, made the daily questionnaire too long, or would not capture their interactions appropriately. Responding to the final questions takes approximately 30 seconds to $2.5 \mathrm{~min}$ utes, depending on the amount of social interaction that day.

Social goals. Participants reported that setting social goals provided an inherent purpose to the app. Some preferred to set individualized goals. However, the majority (75\%) preferred a semi-structured goal-setting tool because they had difficulties in devising goals without prompts. Participants arrived at a consensus that a blend should be implemented. We presented participants a list of real social goals obtained from therapeutic groups with CHR youth (e.g., "talk to someone who is bothering me", "set boundaries", Kelsven et al., 2019), which seemed appropriate for the target users. Participants preferred broad goal categories to avoid feeling overwhelmed by too many options. Changes to the wording were proposed and the number of goals defined. Finally, participants wanted to see the progress towards the completion of their goals. One tab was dedicated to goal creation in a three-step multiple-choice process by selecting: 1) the broad goal (e.g., "motivate myself to go out"); 2) the context (e.g., at home, out in public, at work, or at school); and 3) the person (e.g., brother, girlfriend, mother, teacher, coworker, or classmate). The possibility to write an individualized goal was implemented. Goal improvement was shown via a progress bar with different levels generated by a back-end algorithm, which considers all responses to level-up. Participants entered an activity as a goal, which was then operationalized by entries of the participant. These entries were tracked through a back-end algorithm (i.e., a weighted score based on the responses to each question) that served as a goal improvement proxy (see Supplementary Material eTable 1). Participants found the goal-setting feature easy to understand and representative of the social skills they valued. Participants liked that goals could be customized and were individually tailored. 
Calendar. Participants wanted a calendar for tracking their previous entries. They opted for a traditional view of the month, where a specific day can be selected and responses for that day are displayed. Most participants (87.5\%) reacted against the inclusion of negative feedback in the calendar (e.g., loneliness or days not logged in marked in the calendar). "I don't want to see a red dot on the calendar every day; this would make me feel bad". After some discussion on best methods, days logged in SOMO were marked with a purple circle, and the responses for that day would pop up in a list format.

Feedback. Participants unanimously wanted to have a visual representation of their social functioning as "motivation for not being lazy, using the app, and seeing my progress". Participants preferred different types of data visualizations so they could refer to those most personally useful. Six feedback charts were implemented: (i) run streak of loggings; (ii) quick summary of correlations; (iii) meaningful interactions and loneliness trends by day; (iv) number of interactions with each person; (v) time spent interacting with each person; and (vi) full data of the correlations between activities ${ }^{\star}$ person ${ }^{*}$ meaningfulness. Figure 2 depicts the feedback charts implemented. Participants commented on the importance of streaks in particular, e.g., Snapchat streaks, indicating that this might increase their motivation to use SOMO. Comments included: "I think like err... it would actually become like a competitive thing. How many logs I have?" "It would benefit me; like if I see I'm not logging for four days, I'd be, screw... I need to get on this right now". Moreover, they wanted the negative feedback (e.g., loneliness) to be presented with a soft-line graph rather than numbers: "It is the best way to represent loneliness without coming across as like hurtful to some people; cause if you are really lonely, it's literally a graph, it's not like -hey you've been this lonely-". Feedback regarding time and number of interactions was clear and straightforward, and participants wanted them stratified by type of person. Finally, several iterations of the design of the correlations of meaningful interactions were made until settling on the final grid design. Although not immediately clear, the concept was considered interesting because it is sometimes difficult to figure out the connection between actions and emotions. "There are people that have a hard time to know what made them being lonely, or happy, like what are the things that happen together to make me feel like that."

\section{Usability Testing}

Thirteen participants (nine CHR and four healthy controls; age: $M=20.3, S D=4.6 ; 77 \%$ female) with iOS $(n=8)$ and Android $(n=5)$ devices tested SOMO for one week. Of the 13 participants, four were healthy controls with no prior experience of the app; five CHR participants with no prior experience of the app; and four CHR participants who previously participated in at least one focus group. Quantitative responses of the uMARS after the usability testing are provided in Table 1 . The app had the
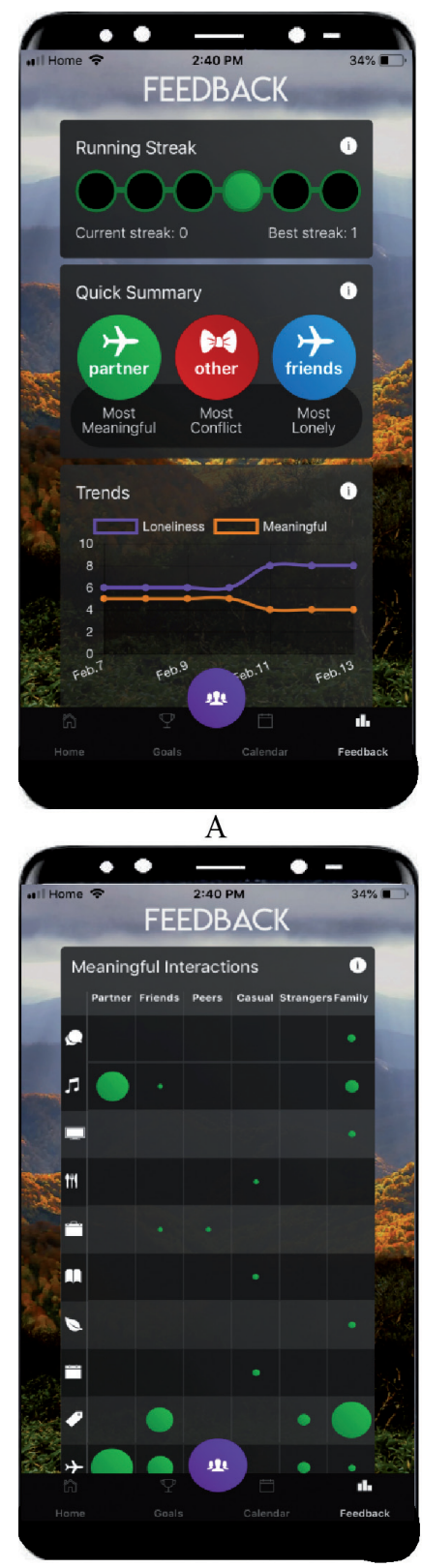

$\mathrm{C}$

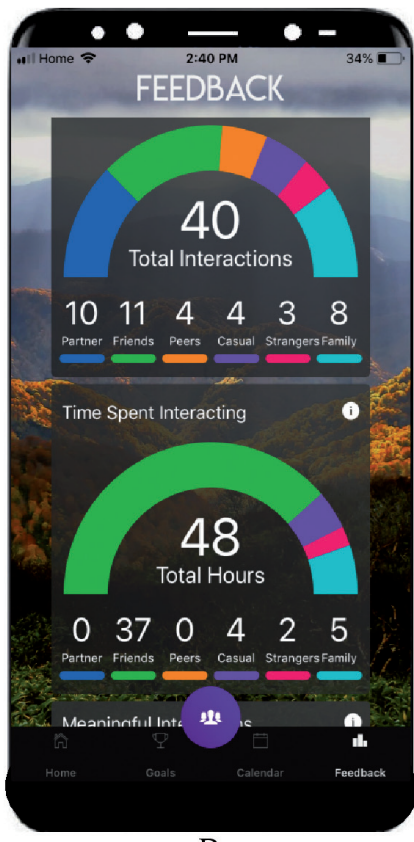

B

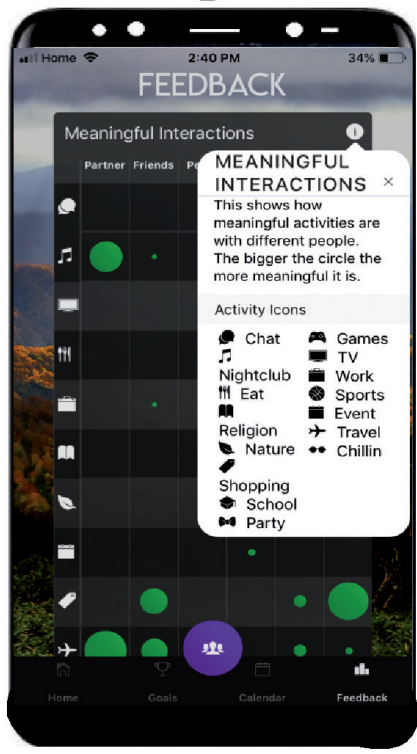

$\mathrm{D}$
Figure 2. Feedback charts: [A] run streak of loggings; meaningful interactions and loneliness trends; and quick summary of correlations; [B] number of interactions with each person; time spent interacting with each person; [C] full data of the correlations between activities ${ }^{*}$ person ${ }^{*}$ meaningfulness; [D] example of an information button.

highest rating in functionality, followed by information provided, aesthetics, subjective information, and engagement, respectively.

Qualitative feedback on the quality of SOMO following the usability testing is presented in Supplementary Material eTable 2. Participants' overall response to the beta version of SOMO was positive. Some technical difficulties and minor bugs were reported, such as the absence of notifications or being unable to create goals, with some Android users unable to save goals 
Table 1. SOMO mean scores on the uMARS $(n=13)$

\begin{tabular}{|lc|}
\hline & $M(S D)$ \\
Engagement & $3.77(0.48)$ \\
Entertainment & $3.08(0.64)$ \\
Interest & $4.08(0.49)$ \\
Customization & $3.15(1.21)$ \\
Interactivity & $4.00(0.82)$ \\
Target group & $4.54(0.78)$ \\
Functionality & $4.65(0.24)$ \\
Performance & $4.08(0.76)$ \\
Ease of use & $4.69(0.48)$ \\
Navigation & $4.85(0.38)$ \\
Gestural design & $5.00(0.00)$ \\
Aesthetics & $4.46(0.66)$ \\
Layout & $4.69(0.63)$ \\
Graphics & $4.31(0.85)$ \\
Visual appeal & $4.38(0.77)$ \\
Information & $4.50(0.38)$ \\
Quality of information & $4.77(0.44)$ \\
Quantity of information & $4.38(0.65)$ \\
Visual information & $4.31(0.63)$ \\
Credibility of source & $4.77(0.60)$ \\
Subjective quality & $4.00(0.74)$ \\
Recommend the app to others & $4.85(0.55)$ \\
Use the app next 12 months & $4.62(0.65)$ \\
Pay for the app & $2.38(1.66)$ \\
Overall app rating & $4.15(0.55)$ \\
Total somo quality & $4.29(0.35)$ \\
Safety & $5.00(0.00)$ \\
\hline
\end{tabular}

Note: uMARS: Mobile Application Rating Scale - user version.

due to a coding problem. Some suggestions for improvement were made: increasing the quality of images and graphics, adding sound, voice, games, more customization options, developing the tutorial, showing the developer credits, and adding extra resources. Common issues identified by the testing sample were addressed in the final version of SOMO, which included four different backgrounds (mountains, ocean, urban, and forest). Small information buttons with further explanation of the app features were added in each tab and for each feedback chart. Some issues could not be addressed, such as increasing the quality of images or adding sound and games. The reasons these issues were not addressed were: 1) concerns of only one user; 2) the difficulty of addressing the issue; 3 ) they surpassed the primary purpose of the app; or 4) installation difficulties. The development team tested the final version of SOMO in-house (alpha testing). All features worked properly for both Android and iOS devices. SOMO was subsequently made available free of charge through Apple Store and Google Play. Although anyone can download the app, a code which is provided only to study participants is needed to create an account. Figure 3 depicts the final SOMO design after gathering participants' feedback.

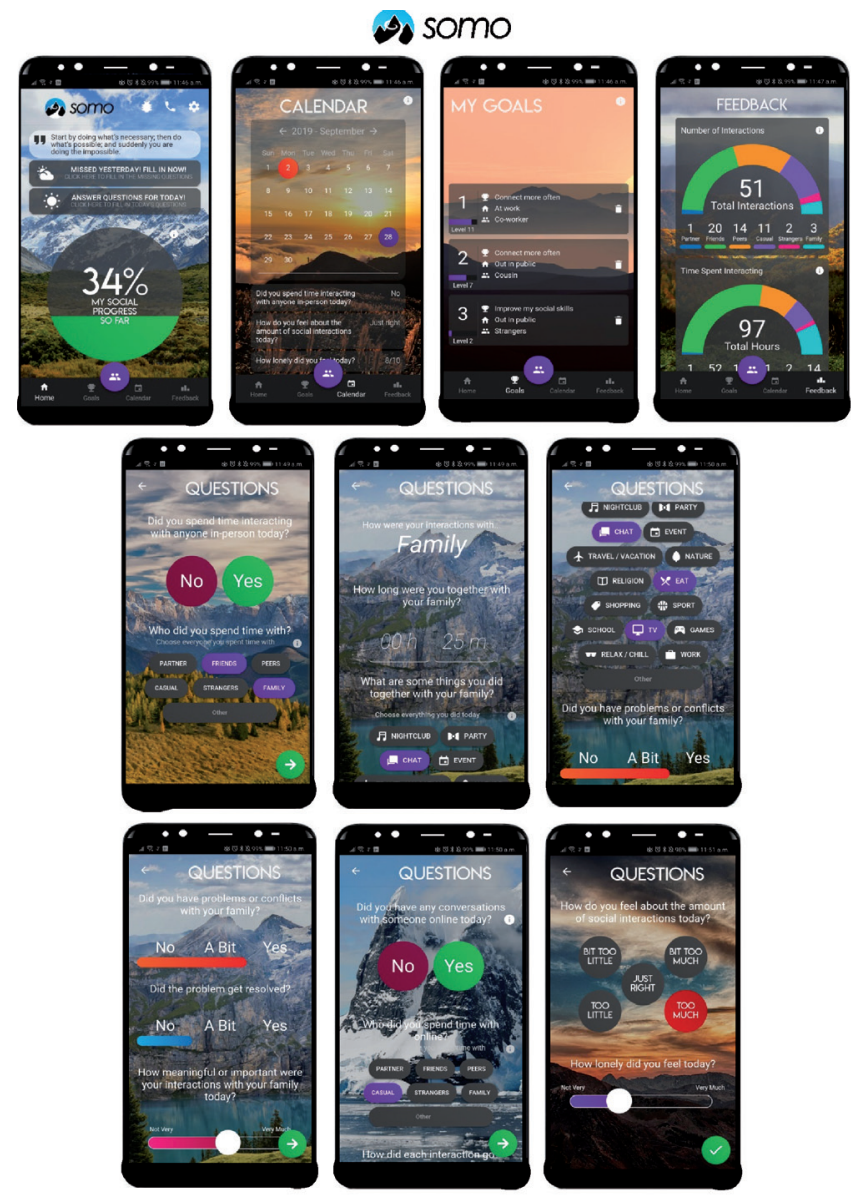

Figure 3. Final SOMO design - Mountains background.

\section{Discussion}

In this paper, we describe the development of SOMO, a mobile application to improve current methods of monitoring social functioning for CHR youth. SOMO conforms to the recommended guidelines for developing apps for research (Bakker, Kazantzis, Rickwood, \& Rickard, 2016). Our prototype has been: (i) co-designed including developer and end-user perspectives; (ii) debugged, iterated, and alpha- and beta-tested; (iii) refined after receiving feedback from end-users regarding design and usability; and (iv) made available in Google and Apple apps stores.

Using a co-design approach for SOMO development improves on the design of available mHealth apps. Although outcomes measured by the app, data integrity, and safety are important aspects for researchers, it is key to assess different characteristics of the app such as functionality or aesthetics (Rickard, Arjmand, Bakker, \& Seabrook, 2016). These aspects are likely to increase user engagement, which is imperative for obtaining final data (Rickard et al., 2016). To do so, well-established app assessment tools (i.e., uMARS, Stoyanov et al., 2016) were employed to develop an app offering standardization and thereby enabling comparison with different mHealth apps. Sat- 
isfaction for SOMO was high, surpassing the mean ratings for 50 mHealth and wellbeing apps for all uMARS subscales (Stoyanov et al., 2015). Specifically, SOMO's highest scores were in functionality (i.e. ease of use, navigation, performance, and gestural design). The Technology Acceptance Model (Davis, 1989) describes that ease of use and perceived usefulness improve engagement with an app and its continued usage. Therefore, SOMO may have a strong potential to maintain engagement.

According to previous research, monitoring was perceived as a safe and acceptable method to gather data on social interactions (Torous et al., 2015) underscoring the need to monitor social functioning from a positive approach (Wadley, Lederman, Gleeson, \& Alvarez-Jimenez, 2013). However, an important concern raised was the fact that monitoring apps do not provide extra support in case of user distress. This echoes similar safety concerns raised by clinicians in other studies (Sundram et al., 2017). Thus, efforts were made to provide links to appropriate services. Despite these considerations, monitoring apps may promote a safe and positive environment for help-seeking and enhance communication with clinicians (Hetrick et al., 2018; Sundram et al., 2017). Moreover, SOMO is password-protected and data is encrypted. Control over privacy settings has been shown to be an important concern for end-users and a key feature in the development of apps for youth (Kenny et al., 2014).

SOMO has a user-friendly design avoiding unnecessary distractions, according with principles proposed previously in the development of apps for individuals with psychosis (Rotondi et al., 2007). This may be important for those who are possibly in the at-risk stages of a psychotic illness. Furthermore, key app features are consistent with evidence-based principles for monitoring tools (Rickard et al., 2016). Customization, control of notifications, and personalization of app features were relevant, and have been addressed as important factors to take into account when co-designing monitoring apps with youth (Hetrick et al., 2018; Sundram et al., 2017). Digital tools that provide greater interactivity, choices, and control may have the potential to enhance acceptability (Knowles et al., 2014).

SOMO includes a goal-setting feature to provide a purpose to the app, which may maximize user engagement, a crucial aspect for mHealth. Following gamification principles (Kapp, 2012), goal improvement is shown via a progress bar with different levels generated by a back-end algorithm, and daily feedback in the form of graphs to users. The provision of feedback on the progress of the desired behavior has been recommended for monitoring and mHealth apps (Bakker et al., 2016). Moreover, daily feedback may increase feelings of achievement, which could be viewed as a reward, and increase engagement with the app (Kapp, 2012). Finally, one of the feedback features included in SOMO is a run streak. Previous research has shown that streaks increase motivation, and are an effective tool to support behavioral repetition, such as creating and maintaining habits (Renfree, Harrison, Marshall, Stawarz, \& Cox, 2016).

To the best of our knowledge, this is the first app to monitor social relationships and social goals following a co-design approach by the inclusion of the target group - CHR youth through focus groups and usability testing. This ensured that the final product was grounded in evidence-based science and provided an engaging, relevant, and useful tool for both Android and iPhone end-users. There are, however, several limitations. Firstly, there are limitations in the app design, where extra customization could have been included to engage more youth. Secondly, there are limitations in the co-design process, where focus groups with independent clinicians and further usability testing with end-users could have been undertaken. One of the difficulties in conducting more than one focus group per theme is that recruiting individuals who meet CHR criteria is difficult (Addington et al., 2008). Moreover, group dynamics such as groupthink may arise in focus groups (i.e. members pressure others to conform to group consensus). To mitigate the recruitment and group dynamics limitations, we performed 13 further individual semi-structured interviews, a method by which study results can reach data saturation (Bernard, 2012; Guest et al., 2006). Other limitations include: (i) a small sample size; (ii) majority of female participants, who may have had a particular design inclination not representing all users' needs and preferences; (iii) a lack of information on the app efficacy due to the development stage of the study; and (iv) a small probability of bias of the usability testing due to the overlap of four participants with the focus group.

Finally, although SOMO was designed following recommended development guidelines, it is key to robustly test the app for efficacy and safety, as well as to assess whether it is a valid and reliable measure of social functioning compared with validated measures for the CHR population such as the Global Functioning: Social (GF:S; Cornblatt et al., 2007).

\section{References}

Addington, J., Epstein, I., Reynolds, A., Furimsky, I., Rudy, L., Mancini, B., Mancini, B., McMillan, S., Kirsopp, D., \& Zipursky, R. B. (2008). Early detection of psychosis: Finding those at clinical high risk. Early Intervention in Psychiatry, 2(3), 147-153.

Addington, J., Farris, M., Stowkowy, J., Santesteban-Echarri, O., Metzak, P., \& Shakeel, M. K. (2019). Predictors of transition in individuals at clinical high risk. Current Psychiatry Reports, 21(6), 39-49.

Addington, J., Liu, L., Perkins, D. O., Carrion, R. E., Keefe, R. S. E., \& Woods, S. W. (2017). The role of cognition and social functioning as predictors in the transition to psychosis for youth with attenuated psychotic symptoms. Schizophrenia Bulletin, 43(1), 57-63.

Addington, J., Stowkowy, J., Liu, L., Cadenhead, K., Cannon, T., Cornblatt, B., McGlashan, T., Perkins, D., Seidman, L., Tsuang, M., Walker, E., Bearden, C., Mathalon, D., Santesteban-Echarri, O., \& Woods, S. (2018). Clinical and functional characteristics of youth at clinical high-risk for psychosis who do not transition to psychosis. Psychological Medicine, 49(10), 1670-1677.

Alvarez-Jimenez, M., Bendall, S., Koval, P., Rice, S., Cagliarini, D., Valentine, L., D’Alfonso, S., Miles, C., Russon, P., Lederman, R., Wadley, G., Killackey, E., Santesteban-Echarri, O., Mihalopoulos, C., Her- 
rman, H., Gonzalez-Blanch, C., Gilbertson, T., Lal, S., Chambers, R., Daglas-Georgiou, R., Cotton, S. M., McGorry, P. D., \& Gleeson, J. (2019). The Horyzons trial: Protocol for a randomised controlled trial of a moderated social therapy to maintain treatment effects from first episode psychosis services. BMJ Open, 9, e024104.

Bakker, D., Kazantzis, N., Rickwood, D., \& Rickard, N. (2016). Mental health smartphone apps: Review and evidence-based recommendations for future developments. JMIR Mental Health, 3(1), e7.

Ben-Zeev, D., Brenner, C. J., Begale, M., Duffecy, J., Mohr, D. C., \& Mueser, K. T. (2014). Feasibility, acceptability, and preliminary efficacy of a smartphone intervention for schizophrenia. Schizophrenia Bulletin, 40(6), 1244-1253.

Bernard, R. H. (2012). Social research methods: Qualitative and quantitative approaches (2nd ed.). Thousand Oaks, CA: Sage.

Braun, V., \& Clarke, V. (2013). Succesful qualitative research. A practical guide for beginners. M. Carmichael (Ed.) London: Sage.

Brucato, G., Masucci, M. D., Arndt, L. Y., Colibazzi, T., Corcoran, C. M., Crumbley, A. H., Crump, F. M., Gill, K. E., Kimhy, D. Lister, A., Schobel, S. A., Yang, L. H. Lieberman, J. A., \& Rirgis, R. R. (2017). Baseline demographics, clinical features and predictors of conversion among 200 individuals in a longitudinal prospective psychosisrisk cohort. Psychological Medicine, 47(11), 1923-1935.

Ciarleglio, A. J., Brucato, G., Masucci, M. D., Altschuler, R., Colibazzi, T., Corcoran, C. M., Crump, F. M., Horga, G., Lehembre-Shiah, E., Leong, W., Schobel, S. A., Wall, M., Yang, L. H., Lieberman, J. A., \& Girgis, R. R. (2019). A predictive model for conversion to psychosis in clinical high-risk patients. Psychological Medicine, 49(7), $1128-1137$.

Cornblatt, B. A., Auther, A. M., Niendam, T., Smith, C. W., Zinberg, J., Bearden, C. E., \& Cannon, T. D. (2007). Preliminary findings for two new measures of social and role functioning in the prodromal phase of schizophrenia. Schizophrenia Bulletin, 33(3), 688-702.

Cornblatt, B. A., Auther, A., Mclaughlin, D., Olsen, R. H., John, M., Christoph, U., \& Oaks, G. (2015). Psychosis prevention: A modified clinical high risk perspective from the recognition and prevention (RAP) program. American Journal of Psychiatry, 172(10), 986-994.

Cornelius, J. B., St. Lawrence, J. S., Howard, J. C., Shah, D., Poka, A., McDonald, D., \& White, A. C. (2013). Adolescents' perceptions of a mobile cell phone text messaging enhanced intervention and development of a mobile cell phone-based HIV prevention intervention. Journal for Specialists in Pediatric Nursing, 360(9346), 1640-1645.

Davis, F. D. (1989). Perceived usefulness, perceived ease of use, and user acceptance of information technology. MIS Quarterly, 13(3), 319-340.

Dennison, L., Morrison, L., Conway, G., \& Yardley, L. (2013). Opportunities and challenges for smartphone applications in supporting health behavior change: Qualitative study. Journal of Medical Internet Research, 15(4), e86.

Fogarty, A. S., Proudfoot, J., Whittle, E. L., Clarke, J., Player, M. J., Christensen, H., \& Wilhelm, K. (2017). Preliminary evaluation of a brief web and mobile phone intervention for men with depression: Men's positive coping strategies and associated depression, resilience, and work and social functioning. JMIR Mental Health, 4(3), e33.

Fusar-Poli, P., Bonoldi, I., Yung, A. R., Borgwardt, S., Kempton, M. J., Valmaggia, L., Barale, F., Caverzasi, E., \& Mcguire, P. (2012). Predicting psychosis: Meta-analysis of transition outcomes in individuals at high clinical risk. Archives of General Psychiaty, 69(3), 220-229.
Granholm, E., Ben-Zeev, D., Link, P. C., Bradshaw, K. R., \& Holden, J. L. (2012). Mobile assessment and treatment for schizophrenia (MATS): A pilot trial of an interactive text-messaging intervention for medication adherence, socialization, and auditory hallucinations. Schizophrenia Bulletin, 38(3), 414-425.

Guest, G., Bunce, A., \& Johnson, L. (2006). How many interviews are enough? An experiment with data saturation and variability. Field Methods, 18(1), 59-82.

Hamzah, A. (2018). The role of participatory design in mobile application development. IOP Conference Series: Materials Science and Engineering, 325(1).

Heary, C. M., \& Hennessy, E. (2002). The use of focus group interviews in pediatric health care research. Journal of Pediatric Psychology, 27(1), 47-57.

Hetrick, S. E., Robinson, J., Burge, E., Blandon, R., Mobilio, B., Rice, S. M., Simmons, M. B., Alvarez-Jimenez, M., Goodrich, S., \& Davey, C. G. (2018). Youth codesign of a mobile phone app to facilitate selfmonitoring and management of mood symptoms in young people with major depression, suicidal ideation, and self-harm. Journal of Medical Internet Research, 20(1), 1-14.

Kapp, K. M. (2012). The gamification of learning and instruction: Gamebased methods and strategies for training and education (1st ed.). San Francisco, CA: John Wiley \& Sons.

Kelsven, S., Holden, J., Devoe, D., Addington, J., Auther, A., Brummitt, K., Cadenhead, K. S., Cornblatt, B., Santesteban-Echarri, O., \& Granholm, E. (2019). Cognitive-behavioral social skills training in youth at clinical high risk for psychosis: Quantitative and qualitative methods: For implementation and facilitator training. Schizophrenia Bulletin, 45(2), S345-346.

Kenny, R., Dooley, B., \& Fitzgerald, A. (2014). Developing mental health mobile apps: Exploring adolescents' perspectives. Health Informatics Journal, 22(2), 265-275.

Knowles, S. E., Toms, G., Sanders, C., Bee, P., Lovell, K., Rennick-Egglestone, S., Coyle, D., Kennedy, C. M., Littlewood, E., Kessler, D., Gilbody, S., \& Bower, P. (2014). Qualitative meta-synthesis of user experience of computerised therapy for depression and anxiety. PLoS ONE, 9(1).

König-Ries, B. (2009). Challenges in mobile application development. Information Technology, 51(2), 69-71.

Lim, M. H., Rodebaugh, T. L., Eres, R., Long, K. M., Penn, D. L., \& Gleeson, J. F. M. (2019). A pilot digital intervention targeting loneliness in youth mental health. Frontiers in Psychiatry, 10(August), 1-13.

McDermott, B., Baigent, M., Chanen, A., Fraser, L., Graetz, B., Hayman, N., Newman, L., Parikh, N., Peirce, B., Proimos, J., Smalley, T., \& Spence, S. (2010). Clinical practice guidelines: Depression in adolescents and young adults. Melbourne, Australia: Beyondblue the National Depression Initiative. Retrieved from: http://www.smartteen. net/main/eng/get_download.php?id=203

McGlashan, T., Walsh, B. C., \& Woods, S. W. (2010). The psychosis-risk syndrome: Handbook for diagnosis and follow-up. New York, NY: Oxford University Press.

Morosini, P. L., Magliano, L., Brambilla, L., Ugolini, S., \& Pioli, R. (2000). Development, reliability and acceptability of a new version of the DSM- IV Social Occupational Functioning Assessment Scale (SOFAS) to assess routine social functioning. Acta Psychiatrica Scandinavica, 101(4), 323-329.

Narad, M. E., Bedell, G., King, J. A., Johnson, J., Turkstra, L. S., Haarbauer-Krupa, J., \& Wade, S. L. (2018). Social Participation and Navi- 
gation (SPAN): Description and usability of app-based coaching intervention for adolescents with TBI. Developmental Neurorehabilitation, 21(7), 439-448.

Pew Research Centre. (2019). Smartphone ownership is growing rapidly around the world, but not always equally. https://doi.org/202.419.4372

Price, M., Sawyer, T., Harris, M., \& Skalka, C. (2016). Usability evaluation of a mobile monitoring system to assess symptoms after a traumatic injury: A mixed-methods study. JMIR Mental Health, 3(1), e3.

Reid, S. C., Kauer, S. D., Dudgeon, P., Sanci, L. A., Shrier, L. A., \& Patton, G. C. (2009). A mobile phone program to track young people's experiences of mood, stress and coping. Social Psychiatry and Psychiatric Epidemiology, 44(6), 501-507.Renfree, I., Harrison, D., Marshall, P., Stawarz, K., \& Cox, A. (2016). Don't kick the habit: The role of dependency in habit formation apps. CHI'16, 1-8.

Rickard, N., Arjmand, H. A., Bakker, D., \& Seabrook, E. (2016). Development of a mobile phone app to support self-monitoring of emotional well-being: A mental health digital innovation. JMIR Mental Health, 3(4), e49.

Rotondi, A. J., Sinkule, J., Haas, G. L., Spring, M. B., Litschge, C. M., Newhill, C. E., Ganguli, R., \& Anderson, C. M. (2007). Designing websites for persons with cognitive deficits: Design and usability of a psychoeducational intervention for persons with severe mental illness. Psychological Services, 4(3), 202-224.

Sanders, E. B. (2002). From user-centered to participatory design approaches. In J. Frascara (Ed.) Design and the social sciences: Making connections (pp. 1-8). London, UK: Taylor \& Francis Books Limited.

Sanders, E. B. N., Brandt, E., \& Binder, T. (2010). A framework for organizing the tools and techniques of participatory design. ACM International Conference Proceeding Series, 195-198.

Scandurra, I., Hägglund, M., \& Koch, S. (2008). From user needs to system specifications: Multi-disciplinary thematic seminars as a collaborative design method for development of health information systems. Journal of Biomedical Informatics, 41(4), 557-569.

Spinuzzi, C. (2005). The methodology of participatory design. Technical Communication, 52(2), 163-174.

Stoyanov, S. R., Hides, L., Kavanagh, D. J., \& Wilson, H. (2016). Mobile Application Rating Scale: User version (uMARS). Young and Well Cooperative Research Centre, 4(2), 1-6.

Stoyanov, S. R., Hides, L., Kavanagh, D. J., Zelenko, O., Tjondronegoro, D., \& Mani, M. (2015). Mobile App Rating Scale: A new tool for assessing the quality of health mobile apps. JMIR MHealth and UHealth, 3(1), e27.

Sundram, F., Hawken, S. J., Stasiak, K., Lucassen, M. F., Fleming, T., Shepherd, M., Greenwood, A., Osborne, R., \& Merry, S. N. (2017). Tips and traps: Lessons from codesigning a clinician e-monitoring tool for computerized cognitive behavioral therapy. JMIR Mental Health, 4(1), e3.

Thomas, D. R. (2006). A general inductive approach for analyzing qualitative evaluation data. American Journal of Evaluation, 27(2), 237-246.

Torous, J., Chan, S. R., Tan, S. Y. M., Behrens, J., Mathew, I., Conrad, E. J., Hinton, L., Yellowless, P., \& Keshavan, M. (2014). Patient smartphone ownership and Interest in mobile apps to monitor symptoms of mental health conditions: A survey in four geographically distinct psychiatric clinics. JMIR Mental Health, 1(1), e5.
Torous, J., Staples, P., Shanahan, M., Lin, C., Peck, P., Keshavan, M., \& Onnela, J. P. (2015). Utilizing a personal smartphone custom app to assess the Patient Health Questionnaire-9 (PHQ-9) depressive symptoms in patients with major depressive disorder. JMIR Mental Health, 2(1), e8.

Wadley, G., Lederman, R., Gleeson, J., \& Alvarez-Jimenez, M. (2013). Participatory design of an online therapy for youth mental health. OZCHI'13.

Warfel, T. (2009). Prototyping: A practitioner's guide. New York, NY: Rosenfeld Media.

\section{${ }^{*}$ Corresponding author}

Dr. Jean Addington, Mathison Centre for Research \& Education, 3280 Hospital Dr. NW, Calgary, AB T2N 4Z6. Canada. Email: jmadding@ ucalgary.ca

\section{Contact information}

Olga Santesteban-Echarri: olgasantestebanecha@ucalgary.ca Jacky Tang: jacky.tang@ucalgary.ca

Jaydon Fernandes: jaydon.fernandes@ucalgary.ca

Jean Addington: jmadding@ucalgary.ca

\section{Declaration of interest}

All authors declare no competing financial and/or personal interests.

\section{Funding Statement}

OSE has been supported by a Canadian Institutes of Health Research and a Short-Term Visiting Fellowship from the Alicia Koplowitz Foundation. This work has been supported by the Calgary Centre for Clinical Research (CCCR) from the Cumming School of Medicine (University of Calgary). The opinions, results, and conclusions are those of the authors and no endorsement by either funding source is intended or should be inferred.

\section{Conflict of Interest}

OSE, JT, JF, and JA list no competing interests 


\section{Supplementary Material}

\section{Functioning Tools}

A wide range of paper tools that measure general functioning, social functioning, and quality of life were consulted to gather items that assessed social functioning in different ways. We presented a selection of items to Focus Group 1 to ascertain if these were appropriate for evaluating social functioning among youth. The following list presents the scales consulted:

- The Social Functioning Scale - SFS ${ }^{1}$

- Functioning Assessment Short Test - FAST ${ }^{2}$

- Social and Occupational Functioning Assessment - SOFAS ${ }^{3}$

- The Quality of Life Mental Health Index - QLI-MH

- Lehman's Quality of Life Interview - QOLI ${ }^{5}$

- Heinrichs' Quality of Life Scale - QLS 6

- The Camberwell Assessment of Need - $\mathrm{CAN}^{7}$

- Children Global Assessment Scale - CGAS ${ }^{8}$

- Comprehensive Quality of Life Scale, School version ComQol-S5 ${ }^{9}$

- Global Assessment of Functioning - GAF ${ }^{10}$

- The Global Assessment Scale - GAS ${ }^{11}$

- The Groningen Social Disabilities Schedule - GSDS ${ }^{12}$ Health of the Nation Outcomes Scales - HoNOS ${ }^{13}$

- Life Chart Schedule - LCS ${ }^{14}$

- McGill Quality of Life Questionnaire ${ }^{15}$

- The MIRECC version of the Global Assessment of Functioning - MIRECC GAF ${ }^{16}$

- Personal and Social Performance - PSP ${ }^{17}$

- Quality of Life Issues - QLI ${ }^{18}$

- Short Screener version of the Social Adjustment Scale - SAS$\mathrm{SR}^{19}$

- Social Inclusion Interview - SII ${ }^{20}$

- Schizophrenia Quality of Life Scale - SQLS ${ }^{21}$

- The Strauss and Carpenter Prognostic Scale ${ }^{22}$

- World Health Organization Disability Assessment Schedule 2.0 - WHODAS $2.0^{23}$

- Wisconsin Quality of Life Index- W-QLI ${ }^{24}$

- Oregon Quality of Life Questionnaire - OQLQ ${ }^{25}$

- Quality of Life Checklist - QLC ${ }^{25}$

- Satisfaction with Life Domains Scale - SDLS ${ }^{26}$

- Community Adjustment Form - $\mathrm{CAF}^{27}$

\section{References}

1. Birchwood M, Smith JO, Cochrane R, Wetton S, Copestake S. The Social Functioning Scale. The development and validation of a new scale of social adjustment for use in family intervention programmes with schizophrenic patients. Br J Psychiatry. 1990;157(6):853-859.

2. Morosini PL, Magliano L, Brambilla L, Ugolini S, Pioli R. Development, reliability and acceptability of a new version of the DSM- IV Social Occupational Functioning Assessment Scale (SO-
FAS) to assess routine social functioning. Acta Psychiatr Scand. 2000;101(4):323-329.

3. Morosini PL, Magliano L, Brambilla L, Ugolini S, Pioli R. Development, reliability and acceptability of a new version of the DSMIV Social and Occupational Functioning Assessment Scale (SOFAS) to assess routine social functioning. Acta Psychiatr Scand. 2000;101(4):323-329.

4. Becker M, Diamond R, Sainford F. A new patient focused index for measuring quality of life in persons with severe and persistant mental illness. Qual Life Res. 1993;2(4):239-251.

5. Lehman AF. Quality of life interview (QOLI). In: Sederer LI, Dickey B, eds. Outcomes Assessment in Clinical Practice. Baltimore: Williams \& Wilkins; 1996:117-119.

6. Heinrichs DW, Hanlon TE, Carpenter WT. The Quality of Life Scale: An instrument for rating the schizophrenic deficit syndrome. Schizophr Bull. 1984;10(3):388-398.

7. Phelan M, Slade M, Thornicroft G, et al. The Camberwell Assessment of Need: The validity and reliability of an instrument to assess the needs of people with severe mental illness. Br J Psychiatry. 1995;167(5):589-595.

8. Shaffer D, Gould MS, Brasic J, Ambrosini P, Bird HR, Aluwahlia S. A Children's Global Assessment Scale (CGAS). Arch Gen Psychiatry. 1983;40:1228-1231.

9. Cummins RA. Comprehensive Quality of Life Scale - Shool Version (Grades 7-12). Melbourne, Australia: School of Psychology Deakin University; 1997.

10. APA. Diagnostic and Statistical Manual of Mental Disorders. 4th ed. (American Psychiatric Association, ed.). Washington, DC; 1994.

11. Endicott J, Spitzer RL, Fleiss JL, Cohen J. The Global Assessment Scale. A procedure for measuring overall severity of psychiatric disturbance. Arch Gen Psychiaty. 1976;33:766-771.

12. Wiersma D, DeJong A, Ormel J. The Groningen Social Disabilities Schedule: Development, relationship with I.C.I.D.H., and psychometric properties. Int J Rehab Res. 1988;11(3):213-224.

13. Wing JK, Beevor AS, Curtis RH, Park SBG, Hadden S, Burns A. Health of the Nation Outcome Scales-(HoNOS). Research and development. Br J Psychiatry. 1998;172:11-18.

14. World Health Organization. The Life Chart Schedule. Geneva: World Health Organization; 1992.

15. Robin Cohen S, Mount BM, Strobel MG, Bui F. The McGill quality of life questionnaire: A measure of quality of life appropriate for people with advanced disease. A preliminary study of validity and acceptability. Palliat Med. 1995;9(3):207-219.

16. Niv N, Cohen AN, Sullivan G, Young AS. The MIRECC version of the Global Assessment of Functioning scale: Reliability and validity. Psychiatr Serv. 2007;58(4):529-535.

17. Nasrallah H, Morosini P, Gagnon DD. Reliability, validity and ability to detect change of the Personal and Social Performance scale in patients with stable schizophrenia. Psychiatry Res. 2008;161(2):213224.

18. Lehman AF. A Quality of Life Interview for the chronically mentally ill. Eval Program Plann. 1988;11:51-62.

19. Gibbons RD, Brown CH, Hur K, et al. Testing the Short and Screener version of the Social Adjustment Scale-Self-report (SAS-SR). J Affect Disord. 2013;69(1):1-10. 
20. Pawson N, Raghavan R, Small N, Craig S, Spencer M. Social inclusion, social networks and ethnicity: The development of the social inclusion interview schedule for young people with learning disabilities. Br J Learn Disabil. 2005;33(1):15-22.

21. Wilkinson G, Hesdon B, Wild D, et al. Self-report quality of life measure for people with schizophrenia: The SQLS. Br J Psychiatry. 2000;177:42-46.

22. Strauss JS, Carpenter WT. The prediction of outcome in schizophrenia. II. Relationships between predictor and outcome variables. Arch Gen Psychiatry. 1974;31:37-42.

23. Üstün TB, Chatterji S, Kostanjsek N, et al. Whodas 2.036 . Bull World Health Organ. 2010;88:815-823.

24. Diamond R, Becker M, D P. The Wisconsin Quality of Life Index: A multidimensional model for measuring quality of life. Psychiatry Interpers Biol Process. 1999;60(S3):29-31.

25. Bigelow DA, Gareau MJ, Young DJ. A quality of life interview. Psychosoc Rehabil J. 1990;14:94-98.

26. Baker F, Intaglaita J. Quality of life in the evaluation of community support systems. Eval Program Plann. 1982;5:69-79.

27. Stein LI, Test MA. Alternative to mental hospital treatment: I. Conceptual model, treatment program and clinical evaluation. Arch Gen Psychiatry. 1980;37:392-397.

\section{Final SOMO questions}

1. Did you spend time interacting with anyone in-person today?

a. Yes (if yes - go to Q2)

b. No (if no - go to Q7)

2. Who did you spend time with? (choose everyone you spent time with) Note: questions Q3-Q6 get repeated for each relation chosen in Q2.
a. Partner
b. Friends
c. Peers
d. Casual
e. Strangers
f. Family
g. Other [write]

3. How were your interactions with... [person] How long were you together with... [person chosen]

a. A 24-hour drop-down menu in hours and minutes.
4. What were some things you did together with... [person] (choose everything you did)
a. Nightclub
b. Party
c. Chat
d. Event
e. Travel/Vacation
f. Nature
g. Religion
h. Eat
i. Shopping
j. Sport
k. School
1. TV
m. Games
n. Relax/Chill
o. Work

5. Did you have problems or conflicts with... [person]?
a. No
b. A bit
c. Yes

6. How meaningful or important were your interactions with your... [person] today?

a. 0-10 slider.

7. Did you have any conversations with someone online today?
a. Yes (if yes - go to Q8)

b. No (if no - go to Q10)

8. In total, how much time did you spend in online conversations today?

a. A 24-hour drop-down menu in hours and minutes.

9. How meaningful were your online conversations?

a. $0-10$ slider.

10. How do you feel about the amount of social interactions today?
a. Bit too little
b. Too little
c. Just right
d. Bit too much
e. Too much

11. How lonely did you feel today? 


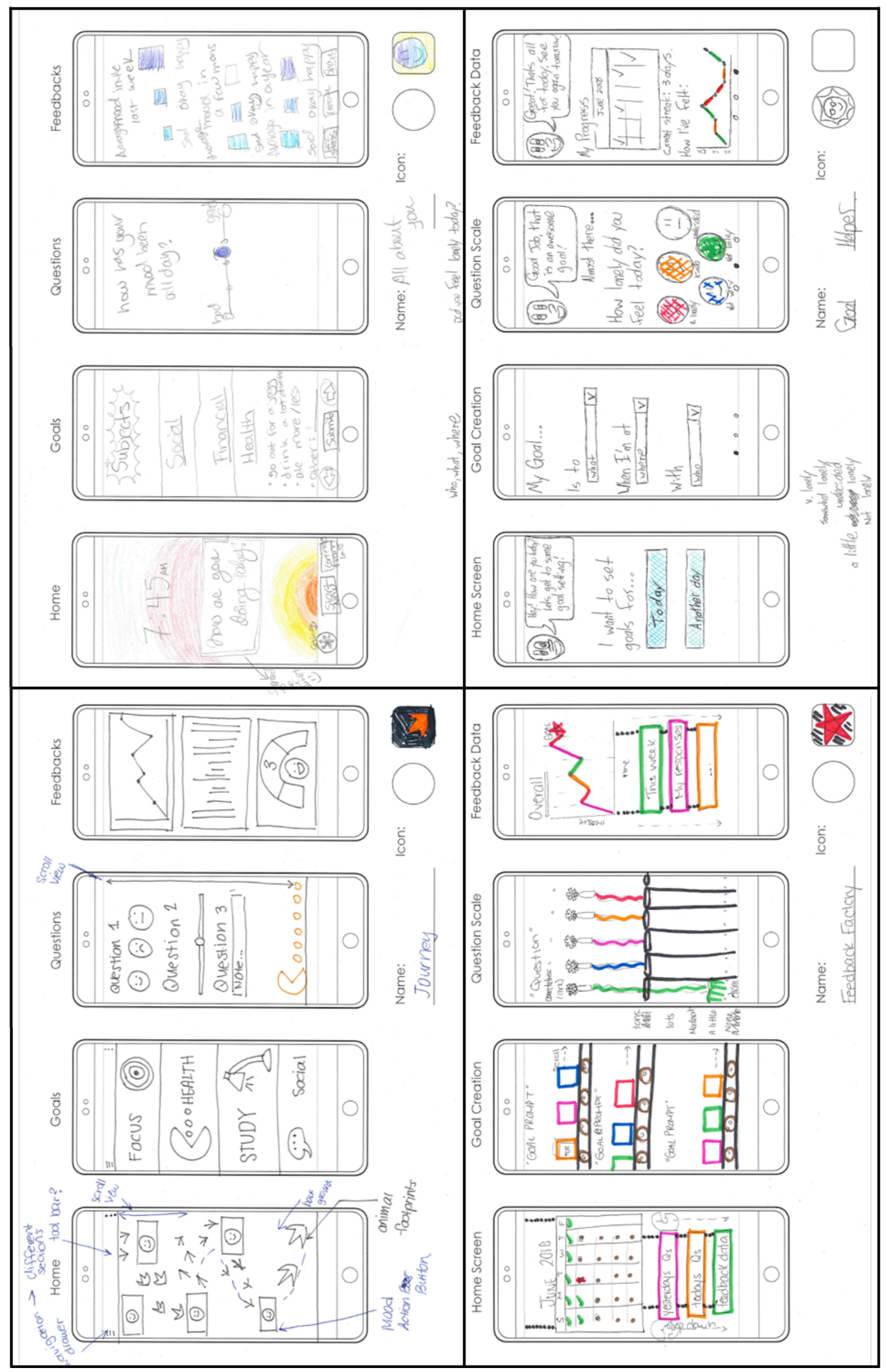

eFigure 1. App sketches produced by participants in the secon focus group.

Note. Permission to publish this material has been obtained. 


\section{Goal Measurement}

To design the back-end algorithm, all social goals are arbitrarily organized into four categories: 1) connection, 2) resolution, 3) expression, and 4) confidence. Each of the 11 daily questions has a weight. eTable 1 depicts the weight of each question. After responding to the questions, a score that only applies to certain goal categories is created. Two questions, with scores ranging from 0 to 10 (Q7: meaningfulness of in-person interactions; Q11: meaningfulness of online interactions), modify the final score. One question (Q1: people), multiplies the final score. The point-multiplier was based on the weight that the Global Functioning Scale: Social (GF:S; Cornblatt et al., 2007) posits to each type of interaction. Each time a participant responds to the daily questions, a score is calculated for each goal created. If relevant to the goal, goal improvement is showed via a progress bar with different levels. The decision-making for the scores was established by two researchers (OSE and JT). In case of discrepancy, a consensus was reached after discussion.

\section{Reference}

Cornblatt, B. A., Auther, A. M., Niendam, T., Smith, C. W., Zinberg, J., Bearden, C. E., \& Cannon, T. D. (2007). Preliminary findings for two new measures of social and role functioning in the prodromal phase of schizophrenia. Schizophrenia Bulletin, 33(3), 688-702.

eTable 1. Algorithm for goal levels

\begin{tabular}{|c|c|c|c|c|c|c|c|}
\hline & & & Goalca & tegory & & & \\
\hline & & Connection & Resolution & Expression & Confidence & & \\
\hline & $<15 \mathrm{~min}$ & 0 & & 0 & 0 & & \\
\hline & $15 \mathrm{~min}-30 \mathrm{~min}$ & 1 & & 1 & 1 & & \\
\hline Q3. Time in- & $30 \mathrm{~min}-1 \mathrm{hr}$ & 2 & & 2 & 2 & & \\
\hline person & $1 \mathrm{hr}-3 \mathrm{hrs}$ & 3 & & 3 & 3 & & \\
\hline & $3 \mathrm{hrs}-6 \mathrm{hrs}$ & 4 & & 4 & 4 & & \\
\hline & $6 \mathrm{hrs}-24 \mathrm{hrs}$ & 5 & & 5 & 5 & & \\
\hline & Chat & 2 & 1 & 2 & 1.5 & & \\
\hline & Relax / Chill & 1 & 0 & 0.5 & 0.5 & & \\
\hline & Games & 1 & 1 & 0.5 & 0.5 & & \\
\hline & TV & 0.5 & 0 & 0.5 & 0.25 & & \\
\hline & Eat & 1 & 1 & 1 & 1 & & \\
\hline & School & 0.5 & 0.5 & 0.5 & 0.5 & & \\
\hline & Work & 0.5 & 0.5 & 0.5 & 0.5 & & \\
\hline Q4. Activity & Event & 2 & 0.5 & 2 & 1 & $0-100 \%$ & fiers \\
\hline & Religion & 1.5 & 1 & 1.5 & 0.5 & Q7. In-person & ningfulness \\
\hline & Travel / Vacation & 2 & 1.5 & 2 & 2 & Q11. Online & ingfulness \\
\hline & Shopping & 0.5 & 0 & 1 & 1 & & \\
\hline & Nature & 2 & 0.25 & 2 & 1 & & \\
\hline & Sports & 2 & 1.5 & 2 & 1.5 & & \\
\hline & Party & 1.5 & 0.5 & 1 & 2 & Point I & lier \\
\hline & Nightelub & 1.5 & 0.5 & 1 & 2 & Q1. & \\
\hline & Yes & & 0 & & & Partner & $200 \%$ \\
\hline Q5. Conflict & A bit & & 0 & & & Friends & $175 \%$ \\
\hline & No & & 1 & & & Peers & $150 \%$ \\
\hline & Yes & & 2 & 2 & & Casual & $130 \%$ \\
\hline Q6. Conflict & A bit & & 1.5 & 1.5 & & Strangers & $120 \%$ \\
\hline & No & & 0 & 0 & & Family & $100 \%$ \\
\hline & Bit too little & 0 & & & 0 & Other & $100 \%$ \\
\hline Q8. & Too little & 0.5 & & & 0.5 & & \\
\hline Subjective & Just right & 1 & & & 1 & & \\
\hline Perception & Bit too much & 1.5 & & & 1.5 & & \\
\hline & Too much & 2 & & & 2 & & \\
\hline $\begin{array}{l}\text { Q9. } \\
\text { Loneliness }\end{array}$ & [Inverse range] & {$[10-0]$} & & & {$[10-0]$} & & \\
\hline & $<15 \mathrm{~min}$ & 0 & & 0 & 0 & & \\
\hline & $15 \mathrm{~min}-30 \mathrm{~min}$ & 0.5 & & 0.5 & 0.5 & & \\
\hline Q10. Time & $30 \mathrm{~min}-1 \mathrm{hr}$ & 1 & & 1 & 1 & & \\
\hline online & 1hr-3hrs & 1.5 & & 1.5 & 1.5 & & \\
\hline & $3 h r s-6 h r s$ & 2 & & 2 & 2 & & \\
\hline & $6 \mathrm{hrs}-24 \mathrm{hrs}$ & 2.5 & & 2.5 & 2.5 & & \\
\hline
\end{tabular}




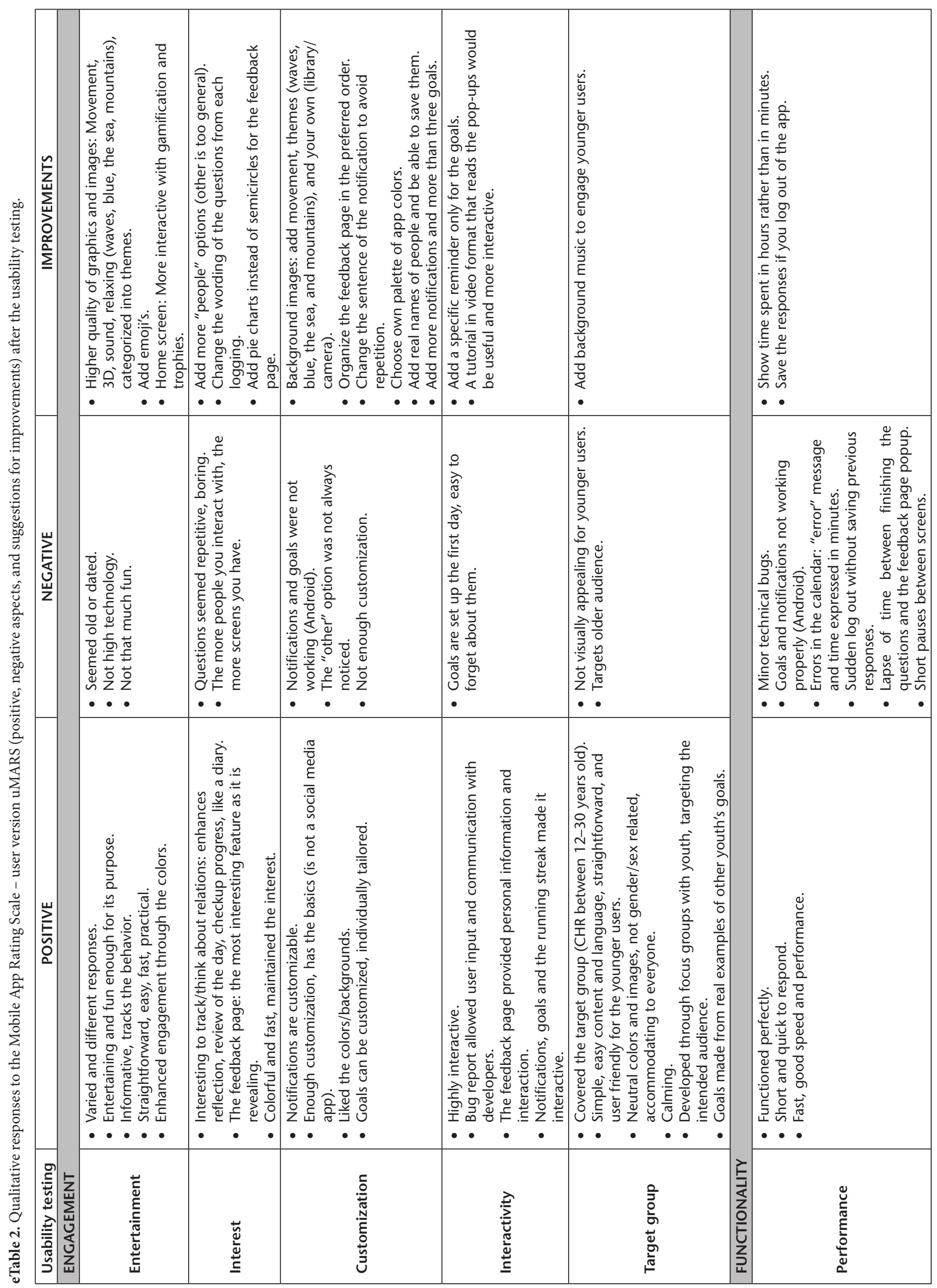




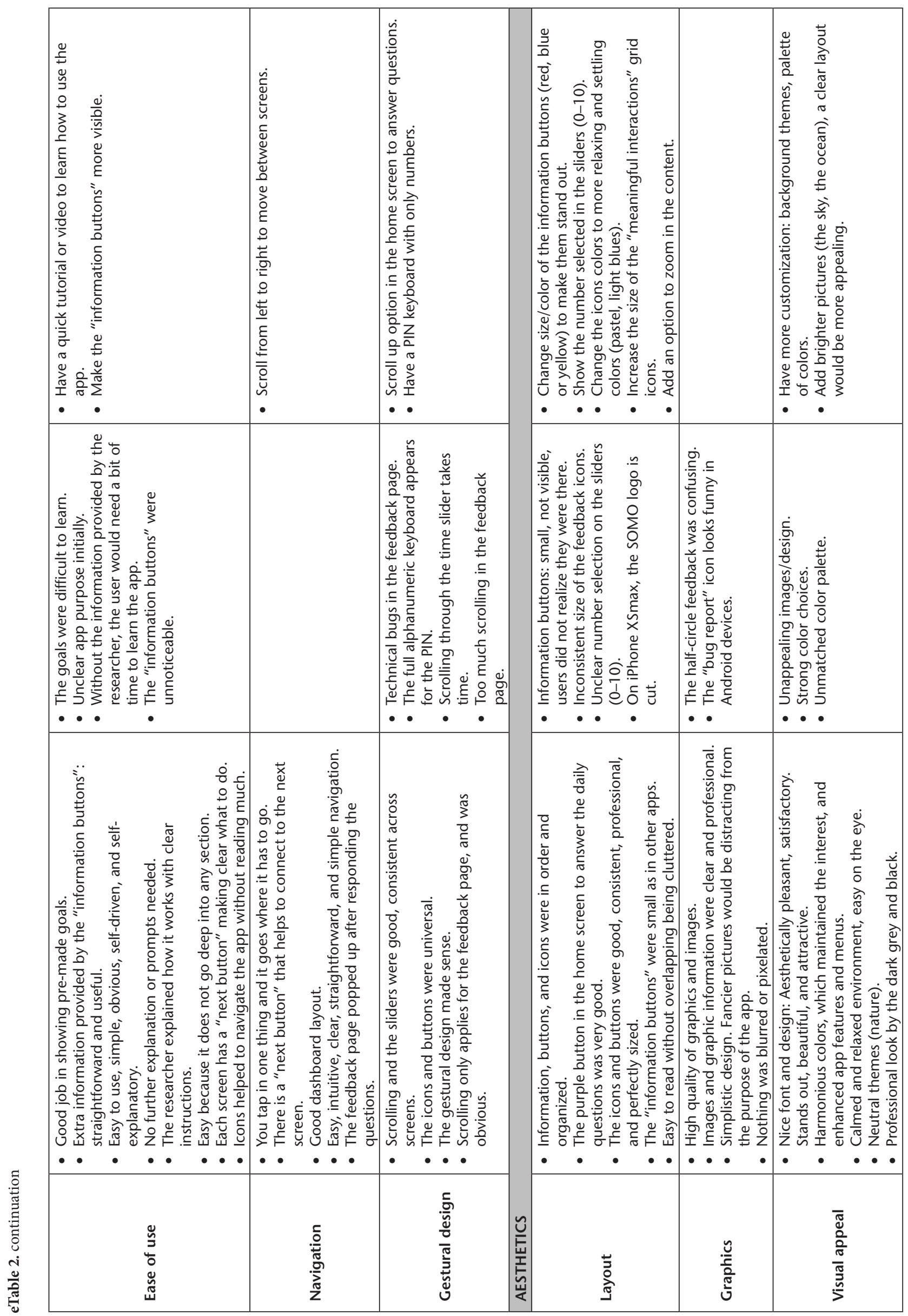




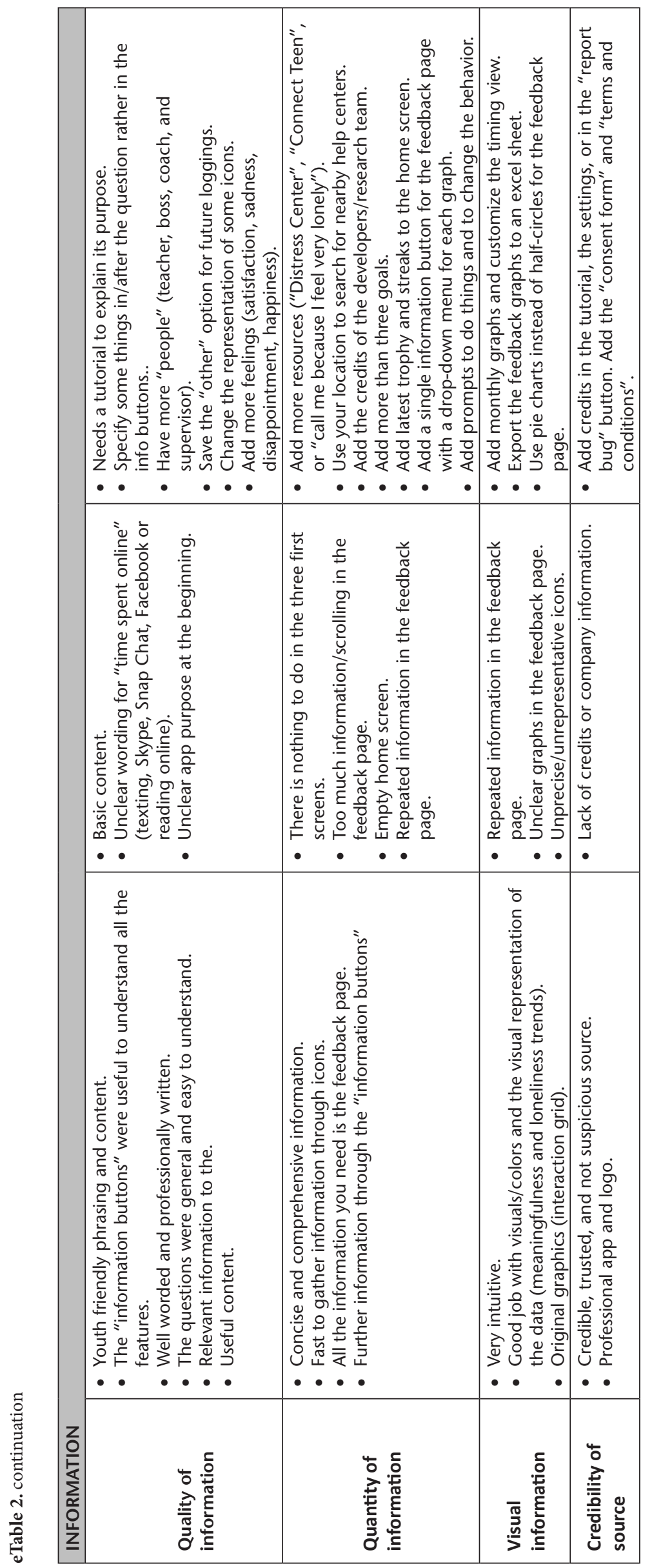

